Хорина Галина Петровна - доктор философских наук, профессор, профессор кафедры истории и регионоведения Московского гуманитарного университета. Адрес: 111395, Россия, г. Москва, ул. Юности, д. 5. Тел.: +7 (499) 374-70-88. Эл. адрес: galhorina@mail.ru

Khorina Galina Petrovna, Doctor of Philosophy, Professor, Department of History and Regional Studies, Moscow University for the Humanities. Postal address: 5, Yunosti St., Moscow, Russian Federation, 111395. Tel.: +7 (499) 374-70-88. E-mail: galhorina@mail.ru

DOI 10.17805/zpu.2018.4.26

\title{
Онтологические основания ценностной детерминации научного познания
}

\author{
Р. А. НурулЛИн \\ КАЗАНСКИЙ (ПРИВОЛЖСКИЙ) ФЕДЕРАЛЬНЫЙ УНИВЕРСИТЕТ
}

Рецензия на книгу: М. В. Клёцкин. Онтологические основания ценностной детерминации научного познания. М. : БИБЛИО-ГЛОБУС, 2018. 290 c. ISBN: 978-5-907063-01-3.

Как отмечается в рецензии, работа посвящена проблеме философского переосмысления аксиологических оснований современной науки. Автор монографии пытается по-новому переосмыслить познавательно-ценностные установки античной философии и вернуть идеи Аристотеля в лоно аксиологических оснований современной науки.

Ключевые слова: рецензия; философия; научное познание; онтология; ценностная детерминация

\footnotetext{
$\Lambda$

анная статья является рецензией на монографию известного самарского исследователя М. В. Клёцкина «Онтологические основания ценностной детерминации научного познания» (Клёцкин, 2018), который работает в области ценностной онтологии научного познания. Аанная работа заинтересовала нас тем, что автор пытается оправдать ценностные аспекты научного познания, априорно закладывая их в сущность самого человека. На этом базисе, следуя тезису: «Новое - это давно забытое старое», он показывает, что аксиологические установки Аристотеля далеко не исчерпали своего потенциала и сегодня на качественно новом уровне своего переосмысления способны составить диалектическое отрицание изжившим модернистским аксиологическим установкам прошлого. Новое возрождение, по мнению автора, обладает большими возможностями как в сфере интерпретации современных физических теорий, так и в сфере практического освоения человеком действительности.

Значение влияния науки на современное состояние общества неумолимо растет. Наука занимает определяющее место в развитии цивилизации и претендует в современном общественном сознании на роль идеологии. Становление науки в самостоятельную форму общественного сознания связано с выведением природы за систему этических отношений, что в свое время было оправданно, но сегодня эти этические установки приводят к истощению природных ресурсов и, как следствие, ставят все человечество перед угрозой собственного уничтожения. Как варварское отношение к природе, так и необдуманное применение научных достижений на практике входят
} 
в перечень глобальных проблем человечества. Перекладывание всех бед человечества лишь на науку было бы, наверное, неверным шагом. Причины необходимо искать в качестве личности самого человека. Поэтому попытка автора аксиологического переосмысления познавательных отношений человека с миром, безусловно, является актуальной.

Во Введении автором обосновывается актуальность темы исследования; раскрывается степень научной разработанности проблемы; выделяются объект, предмет и цель, обосновываются стратегия и тактика, методология, новизна, значимость исследования и др. (там же: 9-29).

В первой главе исследуется история становления ценностной рефлексии (там же: 30-65). Автор анализирует особенности ценностных представлений Античности, Средневековья, Нового времени, Просвещения (там же: 30-39). Констатируется, что современная аксиология рождалась в критическом осмыслении философского наследия Канта. Начиная с работ Шопенгауэра и Маркса, были поставлены основные вопросы, истолкованы основные определения аксиологии. В лице Г. Аотце, О. Кюльпе, $Ф$. фон Визера, А. Аьюи, Р. Перри и др. были предложены множество концепций ценностей. По мнению автора, аксиологический этап развития завершается с изгнанием метафизики из философии благодаря усилиям неопозитивистов.

Вторая глава называется «Онтологические основания ценностного отношения» (там же: 66-133). Здесь автор дает анализ представлений концептов «бытие» и «сущее» Аристотеля, который вместо платоновской идеи на роль посредника в познании сущего предложил концепт «сути бытия». В Новое время различие между бытием и сущим стало выражаться абстрактным различием между субстанциями мыслящей и протяженной, что выхолостило глубокий смысл, заложенный в древнегреческой философии (там же: 66-80). Аалее автор переходит к исследованию психологического аспекта ценностного отношения на основе анализа концепции 3. Фрейда, который поднял значение бессознательного в качестве поля предзаданности смыслов. По мнению автора, взаимодействие между сущим и бытием индивида задают на бессознательном уровне потребности, требующие удовлетворения (там же: 80-106). Аалее исследуется ценностный аспект становления материального бытия. Автор настаивает на том, что бытие вещей всегда носит ценностный характер, так как используется Аля практических целей, что, по мнению автора, тождественно достижению истины (там же: 106-111). Аалее автор переходит к сравнительному анализу онтологических оснований философии Гегеля и Хайдеггера. Отмечает, что у Гегеля, в отличие от Хайдеггера, мышление не сводится исключительно к сознанию, а имеет бессознательный компонент, который он связывает с деятельностью «Абсолютного Ауха» (там же: 111-120).

Третья глава «Ценностный аспект онтологии квантовой механики» (там же: 134-173) начинается с анализа основных положений научной картины мира. Отмечается, что изучение микромира поставило перед физиками философские вопросы: о соотношении потенциального и актуального бытия, о структуре пространства-времени, о вероятностном характере наших знаний (там же: 134-146). Автор рисует картину бытия физических объектов как результат взаимодействия двух начал - сущего-самого-по-себе и мышления ученого (там же: 146-154). Выражает свое скептическое отношение к попыткам ученых выйти за пределы привычных представлений о пространстве-времени путем создания многомерного пространства (там же: 154-160). Аалее автор критикует картезианское представление, которое не видит раз- 
ницы между бытием и сущим-самим-по-себе. Считает, что именно квантовая механика позволяет вернуть физиков к античному пониманию физической реальности и включать на принципах дополнительности как необходимые моменты сущее-самопо-себе, так и мышление этого сущего (там же: 160-171).

В четвертой главе автор пытается построить защиту логической системы Аристотеля (там же: 174-214). По мнению автора, вероятностный характер квантовой физики не противоречит законам аристотелевской логики (там же: 174-185). Он критикует положения аналитической философии, которая при разработке денотативной семантики не учитывает психологические факторы (там же: 185-196). Автор пытается показать актуальность аристотелевской герменевтики для современного познания и убежден, что мышление всегда подчинено задачам использования и изменения сущего в соответствии с потребностями индивида (там же: 196-211).

Пятая глава монографии посвящена ценностным аспектам научного познания и их производности от практики (там же: 215-263). Именно через самореализацию в практике человек познает смысл и истину своего существования (там же: 215-231). Автор считает, что смена классической физики квантовой не является созданием новой онтологии и принципов рациональности, а свидетельствует лишь об эффективности квантовой физики предсказывать и объяснять явления. Считает, что квантовая физика для философов стала поводом для возвращения к античным истокам онтологии (там же: 231-255).

Цюбая работа такого уровня, как бы она ни была хорошо написана, не лишена недостатков, вызванных субъективными мировоззренческими и ценностными особенностями самого рецензента, что вызывает у последнего некоторые вопросы для обсуждения и предложения.

Традиционно ценности определяются как некие идеальные представления в общественном сознании, которые способны мотивировать человека на реальные практические действия. Но на характер формирования общественного сознания способны влиять не только духовные факторы культуры, но и ценности материального мира цивилизации, которые так же, как и ценности культуры, способны определять реальные действия людей. Стремление к материальным благам цивилизации осуществляется посредством идеологии ценностей денег. В эпоху становления информационной цивилизации идеологическое значение духовных ценностей в открытом обществе нивелируется (в силу борьбы между собой различных систем культуры), что позволяет цивилизации (которая в отличие от культуры стремится к масштабной интеграции) беспрепятственно через пропаганду культа денег и потребления распространять приоритет ценностей благ. Это трансформирует всю систему общественных отношений. Все структуры общества, включая и науку, начинают рассматриваться через призму экономической әффективности и быстрого получения материальных выгод. Может быть, сами ученые на индивидуальном уровне и одержимы идеей принести людям практическую пользу от своей деятельности, но результатами их достижений распоряжаются все же менеджеры государства, бизнеса и политических сил, которые одержимы прежде всего стремлением получения практической выгоды.

Практика действительно может служить критерием относительной научной истинны, но сама истина индифферентна по отношению к духовным ценностям как таковым, которые складываются на основе социальной практики. Наука тоже отражает весь мир отношений в идеальных формах, как и духовные ценности других форм 
общественного сознания, которые позволяют людям на основе знаний реально менять свое окружение и создавать цивилизацию. В этом смысле научные знания сами по себе обладают ценностью, но только научной ценностью. Между научной ценностью истины и приложением знаний на практике (которая у автора носит абсолютный характер) существует огромная пропасть, обусловленная несовершенством и незавершенностью истории практики социальных отношений. Определяя ценность через практику, автор сильно рискует оставить в сфере ценностного рассмотрения лишь стремление к достижению практических целей и выключить из рассмотрения влияние духовной составляющей бытия человека. Последняя, как известно, определяется не только наукой. Работа автора написана в духе «оправдания бытия» и, конечно, находится в соответствии с тенденциями современного мира, которые сегодня все более определяются интересами не фундаментальной науки как части культуры, а технонауки и экономики цивилизации. Но все же следует помнить, что цивилизация без духовности рискует быть уничтоженной.

Автор в своей аксиологической концепции не проводит различений специфики влияния духовных и материальных ценностей. По нашим представлениям, эти виды ценностей, будучи противоположными по отношению друг к другу, и по закону, должны существовать на принципах дополнительности. Ауховные ценности, как нам представляется, на индивидуальном уровне сводятся автором лишь к снятию когнитивного диссонанса, неизбежно возникающего в психике субъекта в процессе его познавательной деятельности. Аействительно, научное открытие снимает психическую напряженность сознания человека-ученого и приносит ему чувство удовлетворения. Связано это с тем, что, по мнению автора, человек подключен к сущему-самому-посебе лишь индивидуально, так как каждый через бессознательное и сознательное мышление строит свое индивидуальное бытие-представление о сущем. Истина представлений, по мнению автора, определяется на основе единства представлений множества людей. Вот тут-то и возникают трудности, связанные с установлением согласованных отношений с далеко ненаучными формами ценностей (завистью, страхом, опытом, стереотипами мышления и т. А.). Поэтому в реальности обладателя научной истиной никто не встречает с распростертыми объятиями, а наоборот, научное сообщество в силу организационной консервативности (самосохранения) все сделает, чтобы это знание не стало достоянием практики. Ценность сама по себе действительно устанавливается в результате практических отношений между людьми, которые определяются не только научной целесообразностью, но в большей степени влиянием ценностей вненаучных форм познания - религией, искусством, правом, моралью, философией и др.

Работа написана в духе «оправдания бытия» и связана с переосмыслением научной картины мира в контексте современных тенденций в науке. Современная наука достигла такого уровня своего развития, что сегодня вошла в противоречия со своими аксиологическими основаниями. Эти исходные основания были заложены еще Бэконом. Именно Бэкон, обвинив во всех бедах новоевропейской науки дедукцию Аристотеля, предложил отделить от Бога природу и отдать ее суду инквизиции для пыток, чтобы природа выдала человеку все свои секреты. С природой без Бога стало можно делать что угодно. Так появляется идея испытания природы, которая послужила в Новое время аксиологическим основанием становления науки в самостоятельную форму общественного сознания. Сегодня в эпоху становления информационного общества влияние науки на природу через развитие цивилизации становится тотальным. 
Практическая деятельность по преобразованию природы в угоду удовлетворения материальных нужд производства и потребления сегодня на глобальном уровне стала угрожать физическому существованию всего человечества. Конечно, в возникших проблемах не следует обвинять лишь науку как таковую. Сегодня решение этих проблем невозможно без участия науки. Только наука способна предложить человечеству нелинейные выходы из накопившихся веками проблем, вызванных варварским отношением к природным ресурсам. Но, на наш взгляд, движение в направлении преодоления проблем все же лежит в практике человеческих отношений.

Характер отношений между субъектами определяется не только структурой общества, но также во многом и качествами дичности самих людей, а в особенности тех игроков, в чьих руках находится власть, финансирование и плоды научной деятельности. Сегодня ясно, что аксиологические основания науки требуют своего пересмотра.

Высказанные замечания не умаляют достоинства данной монографии. Работа представляется полной и завершенной, хорошо оформлена и грамотно написана. Концепция выражена отчетливо и определенно. Отвечает всем экстралогическим критериям научности. Широкая эрудиция автора не оставляет сомнений. Автор обладает развитым аналитическим мышлением, а шероховатости возникают лишь тогда, когда авторскую концепцию приходится рассматривать в более широком контексте. На основании произведенных исследований автором высказана оригинальная аксиологическая концепция, в которой гармонично вплетены проблемные аспекты интерпретации неклассических научных представлений. Монография М. В. Клёцкина «Онтологические основания ценностной детерминации научного познания» вносит самостоятельный и оригинальный вклад в обсуждение и решение современных проблем науки.

\title{
СПИСОК АИТЕРАТУРЫ
}

Клёцкин, М. В. (2018) Онтологические основания ценностной детерминации научного познания : монография. М. : БИБАИО-ГАОБУС. 290 с.

Lата поступления: 12.06 .2018 2.

\author{
ONTOLOGICAL FOUNDATIONS \\ OF THE VALUE DETERMINATION OF SCIENTIFIC KNOWLEDGE \\ R. A. NURULLIN \\ KAZAN (Volga REGION) FEDERAL UNIVERSITY
}

A review of the book: M. V. Klyotskin. Ontological Foundations of the Value Determination of Scientific Knowledge. M. : BIBLIO-GLOBUS, 2018. 290 p. ISBN: 978-5-907063-01-3.

As noted in the review, the work is devoted to the issue of philosophical rethinking of the axiological foundations of modern science. The author of the monograph is trying to rethink the cognitivevalue orientations of ancient philosophy in a new way and return Aristotle's ideas to the bosom of the axiological foundations of modern science.

Keywords: review; philosophy; scientific knowledge; ontology; value determination

\section{REFERENCES}

Kletskin M. V. (2018) Ontological Foundations of Value Determination of Scientific Knowledge. Moscow, BIBLIO-GLOBE. 290 p. 
Нуруллин Рафаиль Асгатович - доктор философских наук, профессор кафедры общей философии Института социально-философских наук Казанского (Приволжского) федерального университета. Адрес: 420008, Россия, г. Казань, ул. Кремлевская, А. 18. Тел.: +7 (843) 233-71-58. Эл. aspec: nurulla958@mail.ru

Nurullin Rafail Asgatovich, Doctor of Philosophy, Professor, Department of General Philosophy, Institute of Social and Philosophical Sciences, Kazan (Volga region) Federal University. Postal address: 18, Kremlyovskaya St, Kazan, Russian Federation, 420008. Tel.: +7 (843) 233-71-58. E-mail: nurulla958@mail.ru

DOI 10.17805/zpu.2018.4.27

\title{
Производственно-образовательный кластер как форма взаимодействия органов государственного управления и предпринимательских структур
}

\author{
Ю. Н. ЦАРЕГОРОДЦЕВ \\ МОСКОВСКИЙ ГУМАНИТАРНЫЙ УНИВЕРСИТЕТ
}

Аннотация учебника: Чиркин В. Е. Система государственного и муниципального управления : учебник. 5 изд., перераб. М. : Норма ; ИНФРА-М, 2018. 432 с.

Ключевые слова: государственное управление; муниципальное управление; региональная экономика; кадровый потенциал; человеческий капитал; производственно-образовательный кластер

$\mathrm{B}$ ышло в свет пятое издание учебника В. Е. Чиркина «Система государственного и муниципального управления» для студентов вузов, обучающихся по направлениям «Государственное и муниципальное управление», «Юриспруденция» (Чиркин, 2018). Содержание учебника включает 20 глав, в которых рассмотрены органы, управленческие структуры, особенности и взаимосвязи государственного и муниципального управления; организация государственной и муниципальной службы и роль должностных лиц государственного и муниципального управления. Также рассмотрены функции государственного управления в сфере экономики, социальных и других областях отношений; полномочия органов Российской Федерации, ее субъектов и муниципальных образований; возможности и своеобразие управленческих институтов, процедур и т. А. Вместе с тем представляется, что автор, исследуя результативность деятельности структур управления, недостаточно внимания уделяет оценке реализации или функций в области становления эффективной национальной инновационной системы.

Между тем одним из условий реализации сформулированной Президентом РФ стратегии научно-технологического прорыва является формирование инновационного партнерства государства, предпринимателей, научного и образовательного сообщества, населения. Ведущая роль в партнерстве должна принадлежать государству, которое может обеспечить ее реализацию через систему органов государственного и муниципального управления. Необходимость участия в инновационном партнер- 